\title{
Malignant Fibrous Histiocytoma of the Thoracic Spine Manifesting as Rapidly Progressive Compressive Myelopathy -Case Report-
}

\author{
Hidenobu OCHIAI, Hirokazu KAWANO, Yoshiya SHIMAO*, \\ Tohru HAYASHI*, and Hiroki YAMADA** \\ Departments of Neurosurgery, * Pathology, and \\ ${ }^{* *}$ Radiology, Miyazaki Prefectural Hospital, Miyazaki
}

\begin{abstract}
A 75-year-old woman presented with an extremely rare case of malignant fibrous histiocytoma (MFH) arising in the thoracic spine, causing compression fracture and manifesting as rapidly progressive compressive myelopathy resulting in progressive gait disturbance and weakness of the bilateral legs. Computed tomography and magnetic resonance imaging demonstrated a solid enhanced intravertebral mass destroying the vertebral bodies at the $\mathrm{T} 7$ and T8 levels. Maximum resection of the lesion was performed through wide laminectomy from T7 through T9, followed by vertebroplasty using calcium phosphate paste and posterior fixation with a spinal fixation system. Histological examination showed proliferation of pleomorphic spindle-shaped cells having large irregular nuclei with hyperchromasia with storiform pattern and collagenous stroma, consistent with a diagnosis of MFH. This case illustrates the possibility of rapid maximum decompression surgery from the posterolateral side if MFH manifests as progressive transverse myelopathy.
\end{abstract}

Key words: malignant fibrous histiocytoma, thoracic spine, transverse myelopathy, oncologic emergency

\section{Introduction}

Malignant fibrous histiocytoma (MFH) is a rare primary bone tumor that arises from primitive mesenchymal cells capable of multi-directional differentiation, ${ }^{6,11,17)}$ probably the histiocytes located in the metaphysic or diaphysis of the long bones. ${ }^{2,4,5,9,16)} \mathrm{MFH}$ is aggressive with high rates of local recurrence and metastasis, $, 2,5,7,22)$ and the prognosis is poor with 5-20 year survival rates of $28-33 \% .^{2,4,9)}$ Men are more frequently affected than women and occurrence peaks in the fifth decade. ${ }^{4,16,24)}$ The vast majority of $\mathrm{MFH}$ cases occur in the long bones, such as femur, tibia, and humerus. MFH with spine involvement is rare, but includes cases originating from the paravertebral tissue with secondary extension into the spinal canal, and metastases to the spine. . $^{1,8-8-10,12-15,18-23)}$

Here we describe a case of MFH in a 75-year-old woman referred for treatment of a thoracic spine mass manifesting rapidly progressive weakness of the bilateral legs.

\section{Case Report}

A 75-year-old woman without a previous medical history presented to a local hospital with complaints of back pain and rapidly progressive weakness of the bilateral legs. Computed tomography (CT) demonstrated compression

Received July 7, 2008; Accepted March 13, 2009 fractures of the T6, T7, and T8 vertebral bodies. Her symptoms were progressive and metastatic vertebral bone tumor was suspected, so the patient was referred to our hospital.

On admission, neurological examination revealed tenderness to percussion over the thoracic spine at the T6, T7, and T8 levels. Motor power was $3 / 5$ (manual muscle test) in the bilateral lower extremities. She could not walk. Sensation was decreased to light touch and pin prick in and below the T8 dermatome level. Vibration sense was also decreased in the bilateral lower extremities. Knee and ankle jerks were increased and the bilateral planter extensor reflexes were positive. Preoperative CT and magnetic resonance (MR) imaging confirmed the presence of a mass destroying the vertebral body and extending into the spinal canal at the T6, T7, and T8 levels, appearing as hyperintense on both $\mathrm{T}_{1}$ - and $\mathrm{T}_{2}$-weighted MR images (Figs. 1 and 2). The thoracic spine showed kyphotic change and the thoracic cord was remarkably involved. Metastatic vertebral tumor was first considered, but systemic investigations using positron emission tomography, bone scintigraphy, chest CT, and abdominal ultrasound tomography detected no tumor other than that of the thoracic spine.

Emergent decompressive surgery was performed through a posterior approach. Wide laminectomy from T6 through T8 was performed. The tumor appeared as a whitish, elastic hard, and hypovascular mass, tightly adhered 


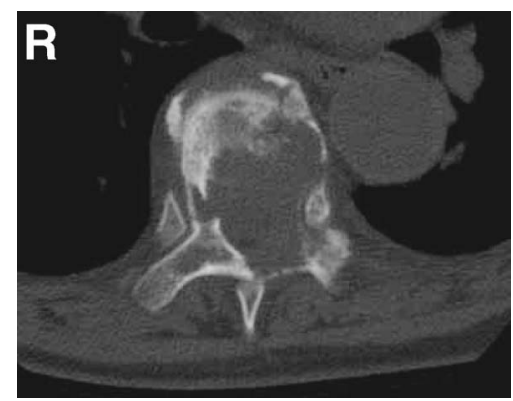

Fig. 1 Axial computed tomography scan demonstrating an osteolytic mass in the T7 vertebral body extending to the spinal canal.
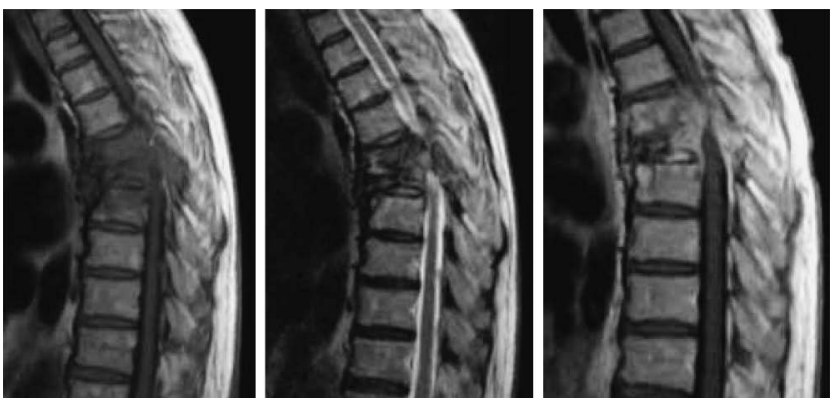

Fig. 2 Sagittal $\mathrm{T}_{1}$-weighted (left), $\mathrm{T}_{2}$-weighted (center), and $\mathrm{T}_{1}$-weighted with contrast medium (right) magnetic resonance images demonstrating compression fractures in the $\mathrm{T} 7$ and $\mathrm{T} 8$ vertebral bodies caused by the intravertebral tumor.

to the dura mater, and compressing the thoracic cord from the left ventrolateral side. The mass did not extend into the adjacent paravertebral soft tissue. The tumor did not bleed much, so near total resection was achieved. Vertebroplasty and posterior instrumentation fusion were performed using calcium phosphate and the Legacy ${ }^{\circledR}$ spinal fixation system (Medtronic Sofamor Danek, Co., Ltd., Osaka). No blood transfusion was necessary. Histological examination showed proliferation of pleomorphic spindle-shaped cells having large irregular nuclei with hyperchromasia with storiform pattern and collagenous stroma (Fig. 3), consistent with a diagnosis of MFH. Postoperative MR imaging demonstrated resection of the tumor and decompression of the thoracic cord (Fig. 4).

After the surgery, weakness of the lower extremities resolved completely and the patient could walk without a cane. The patient received $50 \mathrm{~Gy}$ local radiotherapy to the T6-T8 vertebral bodies and was discharged home.

\section{Discussion}

Primary MFH arising within the spine is quite rare, with only reported 15 cases (Table 1). ${ }^{1,4,8-10,12-15,18,19,22,23)}$ Most cases occurred in the thoracic spine and manifested as back pain. , $10,12,15,18,22,23)$ Neuroimaging showed purely lyt-

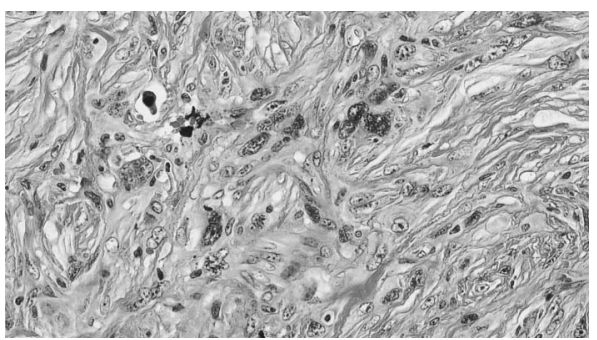

Fig. 3 Photomicrograph showing proliferation of pleomorphic spindle-shaped cells having large irregular nuclei with hyperchromasia with storiform pattern and collagenous stroma. Hematoxylin and eosin stain, original magnification $\times 200$.
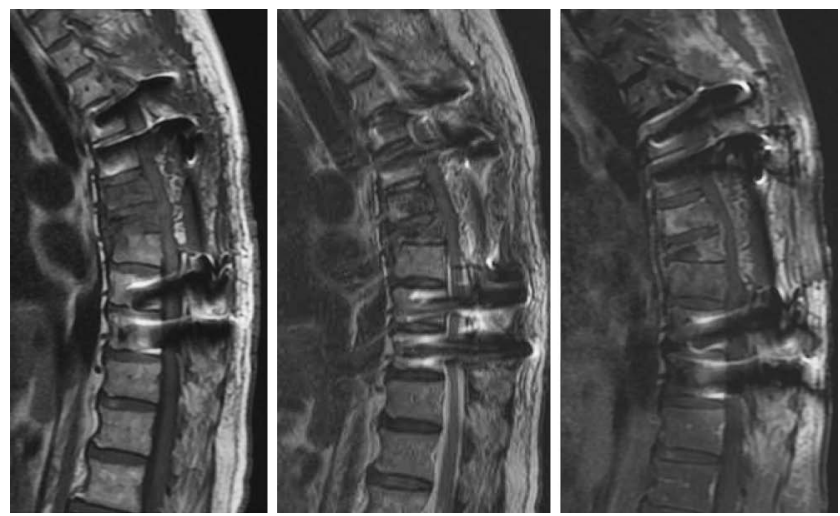

Fig. 4 Sagittal $\mathrm{T}_{1}$-weighted (left), $\mathrm{T}_{2}$-weighted (center), and $\mathrm{T}_{1}$-weighted with contrast medium (right) magnetic resonance images demonstrating resection of the tumor and decompression of the thoracic cord.

ic, expansive lesions with well-defined margins, usually with cortical destruction and soft tissue invasion, but without periosteal reaction or new bone formation.1) The prognosis for primary spine MFH is dismal, and about half of the patients were dead within 15 months. ${ }^{10,14,15,18,19)}$

Differential diagnosis from metastatic lesion is always important for vertebral bone tumor. However, no characteristic neuroradiological features of spinal MFH have been reported, so histological diagnosis and exclusion of other lesions by systemic investigation are necessary. In our case, preoperative imaging and intraoperative findings showed that the tumor was not continuous with the paravertebral soft tissue, and systemic investigation detected no other lesions, so our final diagnosis was MFH of spinal origin.

The present case of spinal MFH manifested as rapidly progressive paraparesis so emergent decompression surgery was essential. The tumor is aggressive with a high rate of local recurrence, so total resection with vertebrectomy is ideal. However, in an urgent situation, maximum tumor resection with vertebrectomy is not always possible for all vertebral tumors. Many of the reported cases of spine MFH underwent wide laminectomy with biopsy as 
Table 1 Summary of reported cases of primary malignant fibrous histiocytoma arising in the spine

\begin{tabular}{|c|c|c|c|c|c|}
\hline Author (Year) & $\begin{array}{l}\text { Age (yrs)/ } \\
\text { Sex }\end{array}$ & Location & Surgical treatment & $\begin{array}{l}\text { Other } \\
\text { treatment }\end{array}$ & Outcome \\
\hline Newland et al. $(1975)^{18)}$ & $74 / \mathrm{M}$ & $\mathrm{T} 8$ & laminectomy + biopsy & RTx & dead (postop day 1) \\
\hline $\begin{array}{l}\text { Kellett and Dearnaley } \\
(1976)^{13)}\end{array}$ & $36 / \mathrm{M}$ & lumbar & laminectomy + biopsy & CTx & terminal stage \\
\hline Dahlin et al. $(1977)^{4)}$ & ?/? & sacrum & ND & ND & ND \\
\hline \multirow{3}{*}{$\begin{array}{l}\text { Teddy and Esiri } \\
(1979)^{23)}\end{array}$} & $52 / \mathrm{M}$ & $\mathrm{T} 10-\mathrm{T} 11$ & laminectomy + biopsy & none & dead (6 mos) \\
\hline & $45 / F$ & $\mathrm{~T} 11$ & laminectomy + biopsy & RTx & alive \\
\hline & $46 / \mathrm{M}$ & T3-T6 & laminectomy + biopsy & RTx & alive \\
\hline Helle et al. $(1983)^{8)}$ & $42 / \mathrm{M}$ & $\begin{array}{l}\text { T10 to } \\
\text { sacrum }\end{array}$ & gross total resection & RTx, CTx & dead (2 mos) \\
\hline Rechtine et al. $(1984)^{19)}$ & $50 / \mathrm{M}$ & $\mathrm{C} 2$ & none & none & dead (2 mos) \\
\hline Huvos et al. (1985) & $? / ?$ & sacrum & ND & ND & ND \\
\hline Itoyama et al. $(1987)^{10)}$ & $65 / \mathrm{F}$ & T1-T2 & subtotal resection & RTx & $\operatorname{dead}(2 \mathrm{mos})$ \\
\hline Bidwell et al. $(1987)^{1)}$ & $17 / \mathrm{F}$ & L5 & biopsy & ND & ND \\
\hline Kepes $(1989)^{14)}$ & $27 / \mathrm{F}$ & $\mathrm{L} 4$ & partial resection & none & dead (a few mos) \\
\hline Sturm et al. $(1992)^{22)}$ & $27 / \mathrm{M}$ & $\mathrm{T} 8$ & total resection & $\mathrm{RTx}$ & alive (16 mos) \\
\hline $\begin{array}{l}\text { Maillefert et al. } \\
(1997)^{15)}\end{array}$ & $40 / \mathrm{F}$ & $\begin{array}{l}\text { T12, L2, } \\
\text { L3, L5 }\end{array}$ & biopsy & RTx, CTx & dead (15 mos) \\
\hline$\underset{(2000)^{12)}}{\text { Karantanas et al. }}$ & $46 / \mathrm{F}$ & $\mathrm{T} 10-\mathrm{T} 11$ & laminectomy + biopsy & CTx & alive (15 mos) \\
\hline Present case & $75 / F$ & T6-T8 & gross total resection & RTx & alive (5 mos) \\
\hline
\end{tabular}

CTx: chemotherapy, ND: not described, postop: postoperative, RTx: radiation therapy.

the initial treatment, ${ }^{1,12,14,15,22,23)}$ with subsequent total vertebrectomy in one case. ${ }^{21)}$ In our case, the tumor did not bleed much, so near total resection of the tumor was possible, followed by vertebroplasty using calcium phosphate paste from the posterolateral approach. In an emergent situation such as our case, decompression of the spinal cord and histological diagnosis are essential to achieve a favorable neurological outcome. The present case suggests that maximum tumor resection might be possible from the posterior approach, and the histological diagnosis can be confirmed as soon as the wide laminectomy is completed. If the intraoperative histological diagnosis is $\mathrm{MFH}$, maximum tumor resection should be considered from the posterior approach to enhance the effect of postoperative chemotherapy or radiotherapy and improve the prognosis.

\section{References}

1) Bidwell JK, Young JW, Saylor L: Malignant fibrous histiocytoma of the spine: computed tomography appearance and review of the literature. J Comput Tomogr 11: 355-358, 1987

2) Capanna R, Bertoni F, Bacchini P, Bacchini G, Guerra A, Campanacci M: Malignant fibrous histiocytoma of bone: the experience of the Rizzoli institute. Report of 90 cases. Cancer 54: 177-187, 1984

3) Choi JY, Kim KN, Kim SE, Yoon DH: Primary malignant fibrous histiocytoma extending into spinal canal through intervertebral foramina. Acta Neurochir (Wien) 146: 415-417, 2004

4) Dahlin DC, Unni KK, Matsuno T: Malignant (fibrous) histiocytoma of bone. Fact or fancy? Cancer 39: 1508-1516, 1977

5) Feldman F, Lattes R: Primary malignant histiocytoma (fibrous xanthoma) of bone. Skeletal Radiol 1: 145-160, 1977

6) Fletcher CDM, Unni KK, Mertens F: Pathology and Genetics of Tumours of Soft Tissue and Bone. Lyon, IARC Press, 2002, pp 294-296

7) Harrington KD: Metastatic disease of the spine. J Bone Joint Surg Am 68: 1110-1115, 1986

8) Helle TL, Hanbery JW, Becker DH: Meningeal malignant fibrous histiocytoma arising from a thoracolumbar myelomeningocele. J Neurosurg 58: 593-597, 1983

9) Huvos AG, Heilweil M, Bretsky SS: The pathology of malignant fibrous histiocytoma of bone: a study of 130 patients. Am J Surg Pathol 9: 853-871, 1985

10) Itoyama $Y$, Fukurama A, Itoh $Y$, Takemura S, Matsukado $Y$, Tanimura A: Spinal malignant fibrous histiocytoma producing cord compression. Neurol Med Chir (Tokyo) 27: 51-55, 1987

11) Iwasaki H, Isayama T, Johzaki H, Kikuchi M: Malignant fibrous histiocytoma. Evidence of perivascular mesenchymal cell origin immunocytochemical studies with monoclonal anti-MFH antibodies. Am J Pathol 128: 528-537, 1987

12) Karantanas AH, Hytiroglou $\mathrm{P}$, Zibis AH, Markonis A, Papadimitriou CS: Malignant fibrous histiocytoma of the spine causing spinal neural foramen widening. Comput Med Imaging Graph 24: 329-332, 2000

13) Kellett RJ, Dearnaley JN: Malignant histiocytoma with diffuse spinal nerve involvement. J Clin Pathol 29: 910-915, 1976

14) Kepes JJ: "Xanthomatous" lesions of the central nervous system: definition, classification, and some recent observations, in Zimmerman HM (ed): Progress in Neuropathology, vol 4. New York, Raven Press, 1989, pp 179-213

15) Maillefert JF, Guy F, Coudert B, Piroth C, Arnould L, Tavernier C: Multifocal malignant fibrous histiocytoma of the spine. Rev Rhum Engl Ed 64: 274-277, 1997

16) McCarthy EF, Matsuno T, Dorfman HD: Malignant fibrous histiocytoma of bone: a study of 35 cases. Hum Pathol 10: 57-70, 1979

17) Nemes Z, Thomazy V: Factor XIIIa and the classic histiocytic markers in malignant fibrous histiocytoma. Hum Pathol 19: 822-829, 1988

18) Newland RC, Harrison MA, Wright RG: Fibroxanthosarco- 
ma of bone. Pathology 7: 203-208, 1975

19) Rechtine GR, Hassan MO, Bohlman HH: Malignant fibrous histiocytoma of the cervical spine. Report of an unusual case and description of light and electron microscopy. Spine 9: 824-830, 1984

20) Reinecke L, Thornley AL: Paraneoplastic paralysis in a patient with malignant fibrous histiocytoma. Br J Clin Pract 46: 203-206, 1992

21) Spanos C, Trigonis S, Aggelidou S, Efstratiou I, Kiskinis D, Syrrakos T: Primary malignant fibrous histiocytoma of the jejunum metastatic to the spine: report of a case. Int J Gastrointest Cancer 35: 143-145, 2005

22) Sturm PF, Abramovitz J, Wagner C, Ferguson R, Walker S: Malignant fibrous histiocytoma of the spine. A case report and review of the literature. Spine 17: 975-977, 1992

23) Teddy PJ, Esiri MM: Malignant fibrous histiocytoma producing spinal cord compression. J Neurol Neurosurg Psychiatry 42: 838-842, 1979

24) Yokoyama R, Tsuneyoshi M, Enjoji M, Shinohara M, Masuda S: Prognostic factors of malignant fibrous histiocytoma of bone. A clinical and histopathological analysis of 34 cases. Cancer 72: 1902-1908, 1993

Address reprint requests to: Hidenobu Ochiai, M.D., Department of Neurosurgery, Miyazaki Prefectural Hospital, 5-30 Kitatakamatsu-cho, Miyazaki, Miyazaki 880-8510, Japan. e-mail: hochiai@fc.miyazaki-u.ac.jp 